\title{
ARTISTS, ARCHIVISTS, AND COMMUNITY
}

Heidi Stalla

Diana Chester

The composition is the thing seen by every one living in the living they are doing, they are the composing of the composition that at the time they are living in the composition of the time in which they are living. It is that that makes living a thing they are doing. Nothing else is different, of that almost any one can be certain. The time when and the time of and the time in that composition is the natural phenomena of that composition and of that perhaps every one can be certain.

Gertrude Stein

In December 2014, artists Diana Chester and Dhanaraj Keezhara put together the exhibition, Every Day Life: A Repertoire of Ritual \& Performance, depicting the lives of Theyyam performers in the village of Keezhara, in Kerala, India. The exhibit draws on archival sound recordings of Theyyam, a ritualistic Hindu Festival, from which Chester composed an immersive sonic environment to match Keezhara's visual compositions. Theyyam performers are traditionally members of a low Hindu caste who have passed down the stories, performances, dances, songs, costumes, and traditions of the festival from generation to generation. Whereas local audience members typically think of the performers in absolute terms (either elevated like gods in their roles as characters of Theyyam, or else as Pulayas, members of a low caste), Chester and Keezhara sought to redirect this gaze by illuminating the lives and activities of the real people who make Theyyam happen.

The two artists are longtime collaborators. They work together to choose compelling moments of everyday experience, create still-life images from these moments, and then highlight the formal properties that best represent the essence of the experiences. They then use these formal properties as maps to create artistic representations in their respective mediums. For example, in one image that was featured in the exhibition a bamboo stick looms large on Keezhara's canvas, bending under the weight of a silver-white fish. This image corresponds to the approaching footsteps of fishermen bringing the day's catch back to temple. The footsteps are heavy and uneven, sonic echoes of the bend and weight of the bamboo pole. In this case, Keezhara and Chester capture an end-of-day moment that feels weighty, yet also brisk and energized, catching and holding the viewer in a continuous moment to which anyone can relate. The hope is that visual art paired with sound will slow down and then heighten sensory experience to allow the audience to focus on a few simple representations of the human condition.

Chester uses archival material as the warp and woof of art designed to reflect and then redirect an intercultural gaze. Some might argue that because this expression ventures into the socio-political realm, and given that original material has been (quite literally) warped and made into performance art, the composition belongs in an exhibition or museum, and no longer in the archive. However, consider Diane Taylor's description in her book, The Archive and the Repertoire, of a rift between archival memory ("items supposedly resistant to change") and repertoire, which "enacts embodied memory-performances, gestures, orality, movement, dance, singing-in short, all those acts usually thought of as ephemeral, nonreproducible knowledge." 13 A repertoire is intangible, unlike a solid object that can be read in or of a particular time and place. A repertoire suggests a collection that can be transferred over time and space. In fact the transference of knowledge is the concern here, as it pertains to the living and changing culture of local and global communities. As humans, we are bent on building silos of knowledge and expertise, categories and classifications that can

I 3 Diana Taylor, The Archive and the Repertoire: Performing Cultural Memory in the Americas (Duke University Press, 2003), 19 
lead to hierarchical power structures. Archival material, catalogued and classified, maintains a semblance of pure form. Taylor writes,

\begin{abstract}
What changes over time is the value, relevance, or meaning of the archive, how the items it contains get interpreted, even embodied. Bones might remain the same while their story may change-depending on the paleontologist or forensic anthropologist who examines them. Antigone might be performed in multiple ways, while the unchanging text assures a stable signifier. Written texts allow scholars to trace literary traditions, sources and influences. Insofar as it constitutes materials that seem to endure, the archive exceeds the "live." 14
\end{abstract}

Archives are created when objects or texts are deemed important to preserve for a particular community. Storing and restoring these artifacts is integral to keeping cultural memory or the impact of an historical event alive. The only thing that keeps the past alive in the present moment is its importance to the community and the way in which it can haunt the present. In effect the past needs to serve as a living shadow of the present.

Art has unique power to inspire universal and powerful modes of expression. By using archival materials, artists can play important roles not only in preserving, recording, and archiving sensitive cultural artifacts, but also in creating new compositions that perpetuate cultural practices by giving them a continuous present in today's rapidly shifting, cosmopolitan, and virtual world. Professional artists can be commissioned to create compositions, which have their own place in the archive alongside the source material. These compositions can also instigate community art projects that promote awareness about the past-and where appropriate - can even be used to pave the way for healing and reconciliation. Taylor describes the positive impact on communities when "people participate in the production and reproduction of knowledge by 'being there,' being a part of the transmission." I5 Connecting members of the community with the material of archives through artistic initiatives helps preserve ephemeral material by revitalizing its relevance and place in a current context and allowing them to perform as artists and interpreters as they compose personal and temporal perspectives about the archival material in and of their generations.

\title{
Form-Shifting
}

Stalla and Chester are developing a particular creative methodology called "form-shifting" that might be useful for archivists who are interested in considering practice-based community arts projects as one way of transferring knowledge.

They have designed workshops in which participants are invited to work with a core original text. Participants recreate the artifact by closely observing its form and structure, its bones so to speak, and using these elements, transform the original piece into a new piece of creative work in mediums or forms that speak best to the participants. So far, in addition to the Theyyam archival field recordings, they have used material ranging from digitized tape collections from Jordan and Oman in the 1980s to mid 20 th Century artifacts and photographs from the Arabian Peninsula, to early drafts and manuscripts of published texts by modernist writers such as Gertrude Stein and Virginia Woolf. This process can create art work that is private or meant for wider viewing; either way subsequent group conversations about the process and the range of interpretations allow for unique moments of discovery and connection with the past. Filtering the bones of archival material through artistic mediums creates a bridge between the past and present that doesn't necessarily exist through heritage or national identity. 


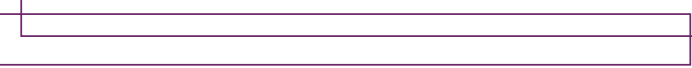

\section{References}

Stein, Gertrude. Composition as Explanation. London:The Hogarth Press, 1926.

Taylor, Diana. 2003. The Archive and the Repertoire: Performing Cultural Memory in the Americas. Duke University Press. 